\title{
Paradox of Flows on Mars
}

\section{L.V. Ksanfomality}

Moscow Space Research Institute, Russia, ksanf@iki.rssi.ru

Using the high-resolution images acquired by cameras onboard the MARS GLOBAL SURVEYOR orbiter made it possible to reveal the previously unknown objects on the Martian surface, which changed dramatically a notion of Mars as a dry, hydrologically dead planet (Malin and Edgett, 2000). Examination of new images shows that the nature of some extended dark formations on the slopes of craters and uplands may be associated with contemporary abundant sources of liquid water arising on the slopes at small depths below the level of surrounding plains.

The presence of liquid water on the surface of Mars is generally considered to be impossible due to low pressure and low temperature on the planet. However there are depressions on the planet's surface where pressure exceeds the critical value required for the existence of liquid water. There are big reserves of underground ice on the planet and conditions for its local conversion into the liquid water. What happens to liquid water on Martian surface? Evaporation plays a negligible role and can be easily assessed, as there is no source of heat for it. Let the pressure in the region be $8 \mathrm{mbar}$ (the corresponding water boiling temperature is $\left.4^{\circ} \mathrm{C}\right)$. Because the heat of evaporation is $540 \mathrm{kkal} / \mathrm{kg}$ and the heat capacity is $1 \mathrm{kkal} /\left(\mathrm{kg}{ }^{\circ} \mathrm{C}\right)$, the evaporated fraction of the flow never exceeds for $1 \%$.
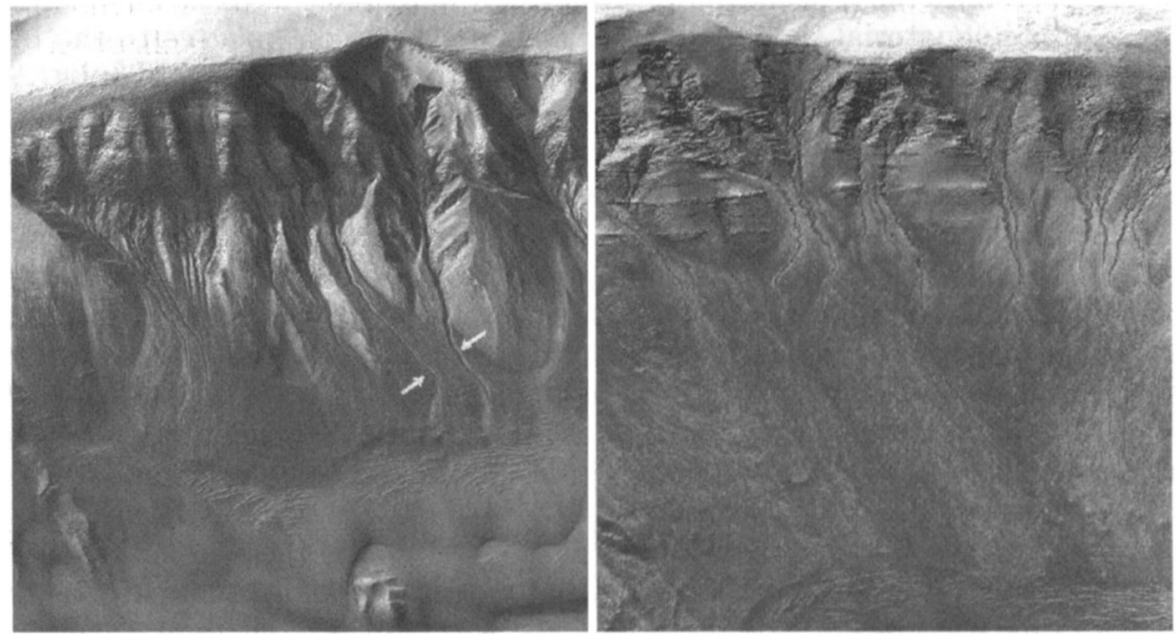

Figure 1. (MGS MOC Release N MOC2-317,320. NASA/JPL/MSSS). 
The structure of extended narrow slope gullies with tributaries, as shown in Fig. 1, which are likely to be produced by water flows, has unusual appearance, reverse to that of terrestrial slope rivers: they are broad in the upper part of the slope, tend to narrow down, terminate as a thin stream and completely disappear at the valley floor or crater floor. The major river beds, as well as tributaries, seem to be directed upslope. The physical explanation of this apparent paradox is simple. Under Martian low temperature of soil and atmosphere, water erupted by springs comes in contact with a very cold ground, is partially absorbed and freezes to form the ice bed on which the flow spreads farther and continues to interact with the cold ground. The flow cools down and an ever-increasing portion of it converts into the ice phase. The distance from the source at which water completely disappears depends on the initial flow temperature and ground temperature. In the equatorial zone, on smooth slopes, such a distance, as images show, may be as large as $6 \mathrm{~km}$. The paradox of side structures is also easily explained: these structures are not tributaries but rather branches where water rapidly freezes.
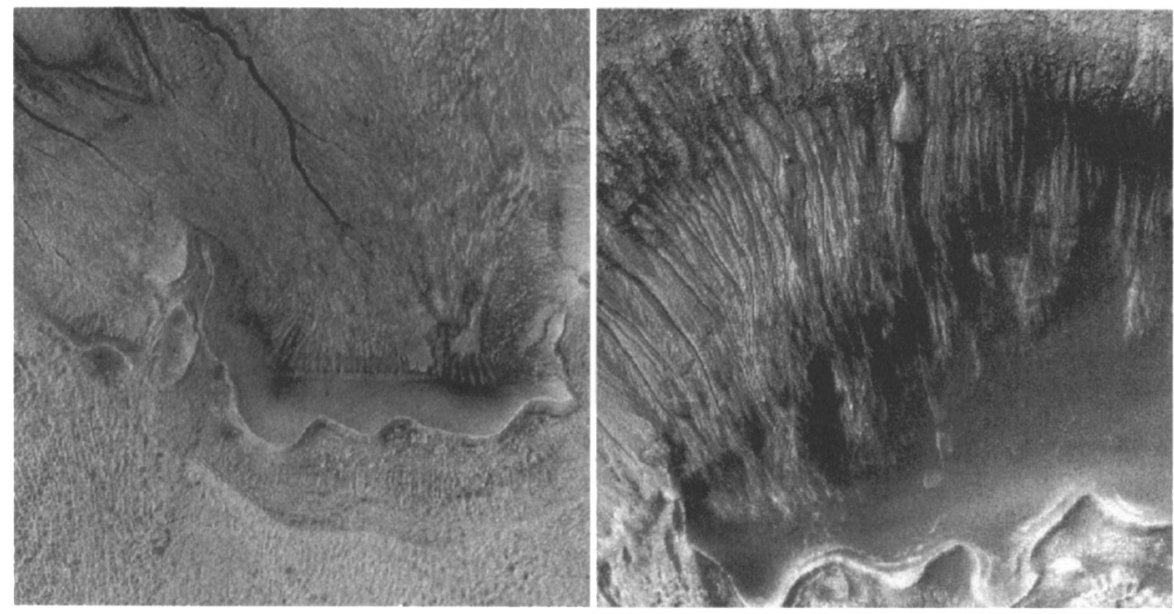

Figure 2. (MGS MOC Release N MOC2-242,320. NASA/JPL/MSSS).

Also detected on the new images are the objects (Fig. 2) that might be small naturally impounded bodies. In the case of a high source debit and/or sufficiently high ambient temperature, a flow-collecting reservoir with walls consisting of a water-saturated frozen ground and ice could arise on the valley floor. Such reservoirs are also known on the Earth (Ksanfomality, 2003), but they are formed from materials stable to positive temperatures.

Mars is a dry and cold planet; however, operating sources and possibly stable ground-water channels are present in some regions. The presence of liquid water, despite the limited character of its sources, can play an important role in the current hydrologic cycles on the planet. If the search of life on Mars should start with the search of water, this issue is probably close to its solution. The concentration of sources of ground water in two equatorial zones of Mars may serve in itself as a useful indicator of places promising for searching life traces on the planet. 


\section{References}

Malin, M. C., and K. S. Edgett 2000, Evidence for recent ground-water seepage and surface runoff on Mars, Science, 288, 2330

Ksanfomality, L.V. 2003, Water Flows and Basins on Mars, Solar System Research, 37, 5 